\title{
RITMO Y TIPOLOGÍA DEL ENDECASÍLABO GARCILASIANO
}

\author{
Miguel Ángel MáRQuez \\ Universidad de Huelva
}

\section{RESUMEN}

Este artículo ofrece una nueva tipología del endecasílabo, basada en su ritmo acentual. En primer lugar, se proponen tres tipos primarios a partir de los acentos identificadores (común, sáfico, y horaciano con acentos en $4^{\mathrm{a}}, 6^{\mathrm{a}}$ y $\left.10^{\mathrm{a}}\right)$. En segundo lugar, se distinguen dos tipos secundarios por la presencia de un acento complementario tras el primer acento identificador (común binario con acentos en $6^{\mathrm{a}}, 8^{\mathrm{a}}$ y $10^{\mathrm{a}}$; y sáfico binario con acentos en $4^{\mathrm{a}}, 6^{\mathrm{a}}, 8^{\mathrm{a}}$ y $\left.10^{\mathrm{a}}\right)$. Por último, los acentos complementarios anteriores al primer acento identificador diferencian diecisiete variedades rítmicas. El análisis de la secuencia de sílabas tónicas y átonas demuestra la existencia en el interior del endecasílabo de una cláusula cuaternaria, que no es reducible a dos cláusulas binarias consecutivas. La musicalidad del endecasílabo se basa tanto en la combinación de cláusulas cuaternarias y binarias tras el primer acento identificador, como en las expresivas variaciones de su inicio.

Palabras clave: Métrica, teoría literaria, endecasílabo, Garcilaso de la Vega, ritmo, tipología y variedades rítmicas.

\section{RYTHM AND TIPOLOGY OF GARCILASO'S HENDECASYLLABLE}

\begin{abstract}
This paper provides a new typology for the hendecasyllable based on its accentual rhythm. I propose three primary types based on the identifying accents (common, Sapphic, and Horatian with accents on the 4th, 6th and 10th syllables). Next, two secondary types will be distinguished by the presence of a complementary accent after the first identifying accent (binary common with accents on the 6th, 8th and 10th syllables; and binary Sapphic with accent on the 4th, 6th, 8th and 10th syllables). Finally, complementary accents prior to the first identifying accent will distinguish seventeen rhythmic varieties within the five types mentioned before. The analysis of the sequence of tonic and atonic syllables will demonstrate the existence of a quaternary clausula, which is not equivalent to two consecutive binary clausulae. The harmony of the hendecasyllable is based both on the combination of quaternary and binary clausulae after the first identifying accent and the expressive variations of its opening.
\end{abstract}

Key words: Metrics, literary theory, hendecasyllable, Garcilaso de la Vega, rhythm, typology, and rhythmic varieties. 
En su fundamental trabajo sobre el endecasílabo, Henríquez Ureña escribió: «Creo que el endecasílabo castellano debe definirse desde el punto de vista de la medida y el acento; no me avengo a ninguna definición que lo presente como verso compuesto de cinco pies acentuales, según se hace todavía, a veces para el endecasílabo italiano. Toda tentativa de explicar la versificación castellana por pies falla en sus fundamentos» ${ }^{1}$. Con su renuncia a explicar el ritmo del endecasílabo más allá de los acentos imprescindibles, Henríquez Ureña se limitó a una clasificación quizá demasiado escueta: tipo A (con acento interior en $6^{\mathrm{a}}$ sílaba) y tipo $\mathrm{B}$ (con acentos interiores en $4^{\mathrm{a}}$ y $8^{\mathrm{a}}$ sílabas). Dentro del tipo $\mathrm{B}$, la forma original llevaría inicialmente sólo acento en $4^{\mathrm{a}}$ sílaba $\left(\mathrm{B}^{1}\right)$, pero después se generarían dos variantes con acentos en $4^{\mathrm{a}}$ y $8^{\mathrm{a}}\left(\mathrm{B}^{2}\right)$ y en $4^{\mathrm{a}}$ y $7^{\mathrm{a}}\left(\mathrm{B}^{3}\right)$.

Por su parte, Navarro Tomás desarrolló su teoría sobre el período rítmico destinada a explicar el ritmo interior de los versos a partir de la alternancia de cláusulas trocaicas y dactílicas: «El endecasílabo es el más largo de los versos simples usados en español. Su primer apoyo rítmico se sitúa sobre las sílabas 1, 2, 3 ó 4. [...]. El período rítmico comprendido entre el indicado apoyo y el acento fijo de la sílaba décima se divide en cuatro partes. A cada parte corresponde una cláusula de una, dos o tres sílabas $»^{2}$. Adaptándose a esa teoría del ritmo, su clasificación se basó implícitamente en el primer apoyo acentual, dando como resultado cuatro tipos: enfático, heroico, melódico y sáfico.

Este artículo pretende revisar esas posiciones sobre la tipología y el ritmo del endecasílabo. Es necesario advertir que el campo de estudio se limita al endecasílabo garcilasiano, entendiendo «garcilasiano» en un sentido lato que incluye a Garcilaso de la Vega, a todos su continuadores en el Siglo de Oro y a la mayor parte de la poesía culta española. Quedan, pues, al margen tanto los endecasílabos que se ensayaron en la poesía castellana durante la Edad Media, sobre todo en el siglo XV, como los endecasílabos «no garcilasianos» que la poesía contemporánea aceptó después del Modernismo.

\section{ACENTOS IDENTIFICADORES Y TIPOS PRIMARIOS}

\subsection{Clases de acentos y tipología}

El ritmo del verso está condicionado por muchos factores pero, sin duda, el número de sílabas métricas y la posición de los acentos son los componentes fundamentales en la versificación española ${ }^{3}$, sobre todo para el endecasí-

\footnotetext{
${ }^{1}$ HENRÍQUEZ UREÑA, Pedro. «El endecasílabo castellano». Estudios de versificación española. Buenos Aires: Instituto de Filología 'Doctor Amado Alonso, 1961, p. 272, nota 1.

${ }^{2}$ NAVARRO TOMÁS, Tomás. Métrica española. Barcelona: Labor, 1983, p. 198.

${ }^{3}$ Cf. DOMÍNGUEZ CAPARRÓS, José. Métrica española. Madrid: Síntesis, 1992, p. 83; TORRE, Esteban. El ritmo del verso. Murcia: Universidad de Murcia, p. 12; y PARAÍSO, Isabel. La métrica española en su contexto románico. Madrid: Arco/Libros, p. 27.
} 
labo, que es un verso que cuenta las sílabas (diez incluyendo la última acentuada), y regula el lugar de sus acentos. Pero no todos los acentos cumplen la misma función y, así, se ha propuesto una clasificación en tres clases: a) acento rítmico, que es el exigido por el metro; b) acento extrarrítmico, que no es exigido por el metro y que no están en posición inmediata a un acento rítmico; y c) acento antirrítmico, no exigido por el metro y en posición inmediata a un acento rítmico.

La distinción entre los acentos rítmico y extrarrítmico es muy clara en un plano teórico, pero en la práctica se vuelve dificultosa, como ha señalado Domínguez Caparrós en su Diccionario de métrica española (s.u. «acento extrarrítmico»):

«Dado que los esquemas a los que se ajustan los distintos tipos de versos no están determinados de forma clara por los tratadistas, es posible encontrar acentos que según los análisis de un autor son considerados como extrarrítmicos, mientras que en los de otro resultan rítmicos» ${ }^{4}$.

La relación entre clases de acentos y tipos rítmicos resulta indisoluble, porque cualquier clasificación tipológica tiene que basarse en una previa definición de los acentos como rítmicos o extrarrítmicos. De alguna manera, se incurre en una tautología al describir el endecasílabo común como aquel que tiene acentos rítmicos al menos en las sílabas $6^{\mathrm{a}}$ y $10^{\mathrm{a}}$, al mismo tiempo que se postula que los acentos en $6^{\mathrm{a}}$ y $10^{\mathrm{a}}$ sílabas son acentos rítmicos en el endecasílabo común porque son exigidos por el patrón métrico. Pero al margen de esa circularidad de pensamiento, a partir de los tipos básicos descritos tradicionalmente (endecasílabo común o «a maiori» y endecasílabo sáfico o «a minori»), es posible distinguir tres clases de acento:

a) necesario: es el acento final en $10^{\mathrm{a}}$, que aparece en todos los endecasílabos;

b) identificador: acento que obligatoriamente aparece en cada tipo rítmico y que lo define (acento en $6^{\mathrm{a}}$ para el común; acentos en $4^{\mathrm{a}}$ y $8^{\mathrm{a}}$ para el sáfico);

c) complementario: acento facultativo para cada tipo (por ejemplo, antes del acento identificador, acento en $1^{\mathrm{a}}, 2^{\mathrm{a}}$ o $3^{\mathrm{a}}$ para el común; acento en $1^{\mathrm{a}}$ o $2^{\mathrm{a}}$ para el sáfico).

\footnotetext{
${ }^{4}$ Sobre la terminología métrica a la que se ha hecho referencia, cf. DOMÍNGUEZ CAPARRÓS, José. Diccionario de métrica española. Madrid: Alianza, 2007. En su Métrica española, Domíngue Caparrós enuncia también la misma idea: «Si la calificación de 'rítmico', 'extrarrítmico' y 'antirrítmico' se hace depender de las normas del modelo de verso, y si sabemos que, por lo que se refiere a la acentuación, hay propuestas distintas para explicar su organización rítmica, entonces no puede sorprender que la divergencia en la consideración de algunos acentos como rítmicos en un modelo y como extrarrítmicos o antirrítmicos en otro» (DOMÍNGUEZ CAPARRÓS, José. Métrica española. Madrid: Síntesis, 1993, p. 96).
} 
Para ejemplificar esa clasificación, véanse los siguientes versos:

Todas, con el cabello desparcido $(225)^{5}$

de robles y de peñas varïando; (172)

Alegrando la hierba y el oído (64)

De la esterilidad es oprimido (345)

Los cuatro son endecasílabos comunes, pues en todos se acentúan las sílabas $6^{\mathrm{a}}$ (acento identificador del tipo rítmico) y $10^{\mathrm{a}}$ (acento necesario). Antes del acento en $6^{\mathrm{a}}$, pueden tener un acento complementario en $1^{\mathrm{a}}, 2^{\mathrm{a}}$ o $3^{\mathrm{a}}$ sílaba, o carecer de él (verso 345). Sin cualquiera de eso acentos complementarios, el verso sigue siendo un endecasílabo común, pero si falta el acento en $6^{a}$ deja de serlo ${ }^{6}$. El mismo análisis cabe hacer con el endecasílabo sáfico. Véanse los siguientes versos:

vido de flores y de sombras lleno (72)

cestillos blancos de purpúreas rosas (222)

con la fineza de la varia tinta (115)

Los tres versos anteriores presentan los mismos acentos identificadores en $4^{\mathrm{a}}$ y $8^{\mathrm{a}}$ sílaba, además del acento necesario en $10^{\mathrm{a}}$. El verso 115 no tiene ningún otro acento, pero en los versos 72 y 222 recae un acento complementario en $1^{\mathrm{a}}$ y en $2^{\mathrm{a}}$ sílaba respectivamente.

\subsection{Acentos antirrítmicos}

Por su parte, los acentos antirrítmicos, que serían los acentos prosódicos situados en posición inmediata a un acento rítmico, implican una elevación del tono que se presenta junto a la del acento rítmico, que en esas condiciones deja de estar rodeado de sílabas con un tono más bajo. En este sentido, resulta muy pertinente la anotación de Quilis:

${ }^{5}$ Todos los ejemplos se han tomado de la Égloga III de Garcilaso de la Vega, salvo cuando se especifica otra fuente distinta. Después de la cita, entre paréntesis aparece el número de verso. Seguimos la edición de Rivers (RIVERS, Elias L. Garcilaso de la Vega. Poesías castellanas completas. Madrid: Castalia, 1984), a pesar de que no es por completo coherente en algunos aspectos importantes para la métrica. Por ejemplo, las diéresis en la palabra «suave» se marca en el verso 295 («las verdes selvas con el son süave»), pero no en el 285 («suave y dulcemente detenidos»), donde sería necesario marcarla para distinguir la escasión de ese verso de la del verso 74, donde no se produce diéresis («el suave olor d'aquel florido suelo»). Por otra parte, en el verso 359, hemos preferido la edición de Herrera (HERRERA, Fernando. Obras de Garcilaso de la Vega con anotaciones. Edición facsímil. Sevilla: Universidades de Córdoba, Huelva y Sevilla, 1998): «do quiera que d'oi más sauces se hallen», porque la de Rivers, «doquiera que sauces de hoy más se hallen», no cumple el patrón acentual.

${ }^{6} \mathrm{Si}$ faltase el acento en $10^{\mathrm{a}}$ no sería ni siquiera un endecasílabo. 
«Téngase en cuenta que el término antirrítmico, como los demás, sólo se refiere a una determinada situación de las sílabas acentuadas, no indica una falta contra la estética del verso; como todos los recursos de la versificación, este acento antirrítmico se justifica cuando se usa para conseguir un efecto estilístico» ${ }^{7}$.

Es indudable la capacidad expresiva de esos acentos que concurren inmediatamente al acento necesario o a los acentos identificadores. De hecho, son susceptibles de producir efectos estilísticos admirables cuando son utilizados por los grandes poetas ${ }^{8}$. Sin embargo, su naturaleza ha sido motivo de debate. Para García Calvo, esos acentos prosódicos no rítmicos conservarían la elevación del tono que les corresponde, pero no cumplirían ninguna función rítmica en el verso 9 . Por el contrario, Isabel Paraíso sugiere una pérdida de tonicidad del acento antirrítmico:

«Acento antirrítmico es el que se halla en contigüidad con un acento rítmico, a menudo precediéndole. Al encontrarse así dos sílabas tónicas en contacto, una por motivación gramatical y la otra por motivación gramatical y rítmica, suele desacentuarse parcialmente la primera (desacentuación rítmica secundaria)» ${ }^{10}$.

En cualquier caso, al margen de la repercusión que el acento antirrítmico pueda tener en la curva tonal, se admite universalmente su función expresiva, pero se excluye que pueda jugar algún papel en el establecimiento del

7 QUILIS, Antonio. Métrica española. Barcelona: Ariel, 1984, p. 36 nota 10. Entendemos que el prefijo «anti-» es adecuado porque el acento antirrítmico presenta su elevación de tono «frente a» la del acento rítmico, no porque ese acento se oponga a la euritmia.

${ }^{8}$ Así, Navarro Tomás anota: «Hay ocasiones entre las sílabas impares en que alguna de ellas, la séptima especialmente, recibe un acento gramatical que, aunque fuera de la línea del ritmo, desempeña un papel activo como elemento de expresión» (NAVARRO TOMÁS, Tomás. «La musicalidad de Garcilaso». Los poetas en sus versos. Barcelona: Ariel, 1982, pp. 143-144).

9 «Tomemos una frase como Te mando mil besos, en que hay tres tónicas; señalémoslas: Te mándo míl bésos. Como las dos últimas están contiguas, no pudiendo consentir el ritmo en el lenguaje hablado [...] dos tiempos marcados inmediatos [...] sucede que sólo en la segunda de las dos se marca el ritmo; pero ello en modo alguno implica que la palabra mil pierda su acento (nada impide, en efecto, que haya dos notas 'altas' contiguas), sino que lo guarda y realiza como en cualquier otra posición» (GARCÍA CALVO, Agustín. Del ritmo del lenguaje. Barcelona: La Gaya Ciencia, 1975, p. 31.

${ }_{10}$ PARAÍSO, Isabel, op. cit. p. 83. Ahora bien, Paraíso distingue el acento antirrítmico del acento enfático; cuando el choque de dos acentos sirve como medio expresivo, Paraíso postula que ambos acentos deben mantenerse por razones estilísticas, intercalando una ligerísima pausa para ambos acentos sean perceptibles (Paraíso, op. cit. pp. 83-84). Con respecto a la desacentuación del acento antirrítmico, véase igualmente NÚÑEZ RAMOS, Rafael. «Para un modelo abstracto del endecasílabo castellano». Dispositio, vol. III, n. ${ }^{\circ} 7-8$, pp. 157-165. E. Torre ha postulado una idea similar a la defendida por Paraíso. Según Torre, en los casos en los que concurren dos acentos contiguos, teniendo en cuenta que el tono de cada sílaba depende del entorno, una de las dos sílabas sería más relevante por el tono y asumiría la función rítmica en el verso (TORRE, Esteban. Métrica española comparada. Sevilla: Universidad de Sevilla, 2000, p. 49). 
patrón acentual. En resumen, aplicando esta clasificación de los acentos a un verso de Garcilaso de la Vega, quedará patente el punto de partida teórico de este trabajo:

$$
\text { y cómo, después desto, él impaciente (141) }
$$

En este verso, junto al necesario acento final, el acento identificador recae en las sílabas $6^{\mathbf{a}}$ (endecasílabo común). Un acento complementario en la sílaba $2^{\text {a }}$, que no es obligatorio puesto que podría recaer en otra sílaba o faltar, determina que nos hallamos ante la variedad rítmica del endecasílabo heroico. Por último, los acentos prosódicos en $5^{\mathrm{a}}$ y $7^{\mathrm{a}}$ sílabas son antirrítmicos porque concurren con el acento de $6^{\mathrm{a}}$ sílaba, son irrelevantes para la tipología rítmica y sólo atañen a la singularidad de ese verso, aunque por eso mismo podrían resultar muy expresivos ${ }^{11}$.

\subsection{El endecasílabo con acento en $4^{a}$ y $6^{a}$ sílabas}

Generalmente se ha postulado que, en la poesía de Garcilaso de la Vega y en toda la poesía culta española que sigue su modelo, se combinan dos tipos rítmicos primarios del endecasílabo: el común (con acento en $6^{\mathrm{a}}$ ) y el sáfico (con acentos en $4^{\mathrm{a}}$ y $8^{\mathrm{a}}$ ), es decir, los tipos (A) y $\left(\mathrm{B}^{2}\right)$ de la clasificación de Henríquez Ureña. Está tipología tan simple se complica en los versos que presentan acento en $4^{\mathrm{a}}, 6^{\mathrm{a}}$ y $10^{\mathrm{a}}$ sílabas, muy frecuentes como ya señaló Navarro Tomás. Parte de la crítica considera que esos versos son endecasílabos comunes, por una supuesta prevalencia del acento en $6^{\mathrm{a}}$ sílaba. Sin embargo, Navarro Tomás postuló que se trataba de endecasílabos sáficos. Isabel Paraíso ha desarrollado esta idea:

«En los endecasílabos 'a minore', horacianos o sáficos, el acento constituyente en sílaba $4^{\mathrm{a}}$ está acompañado por el final, en $10^{\mathrm{a}}$, y también por dos acentos flotantes cuya posición es variable: $1^{\mathrm{a}}$ o $2^{\mathrm{a}}$ sílaba el primero, y $6^{\mathrm{a}}$ u $8^{\mathrm{a}}$ el segundo. [...]. Caso especial son aquellos endecasílabos que acentúan tanto en $4^{\mathrm{a}}$ como en $6^{a}$, pues podemos plantearnos el problema de si son de tipo sáfico o de tipo heroico. Nos parece preferible considerarlos sáficos, por ser posible para el sáfico acentuar en $6^{\mathrm{a}}$, pero no al revés» ${ }^{12}$.

Veamos algunos ejemplos en la primera estrofa de la Égloga III después de la dedicatoria:

${ }^{11}$ Un comentario estilístico nos haría ver que la concurrencia de tres acentos prosódicos, acompañada de una homeopróforon de dentales, resulta muy adecuada para la expresión de la angustia impaciente de Orfeo en su subida al mundo de la luz sin poder mirar a su amada Eurídice. Sin embargo, como el objetivo de este trabajo no consiste en ofrecer un comentario estilístico, sino en clasificar tipológicamente los endecasílabos, anotando sus variedades rítmicas, los acentos llamados antirrítmicos o expresivos no serán tomados en cuenta en adelante.

12 PARAÍSO, Isabel, op. cit. pp. 128-129. 


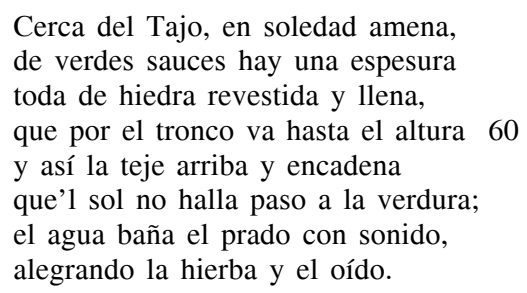

Frente a los versos 57 y 59 netamente sáficos, Dámaso Alonso comentó en Poesía española la ambigüedad rítmica de los versos 58 y 60, que sonaban inicialmente sáficos aunque después presentaban acento en $6^{\mathrm{a}}$ sílaba y no en $8^{\mathrm{a}}$, defraudándose la expectativa generada por el acento en $4^{\mathrm{a}}$ sílaba.

«Nada hay que aclarar en los versos primero [57] y tercero [59], de normal acentuación en cuarta y octava sílabas. Pero ¿acaso no cometemos error en los otros dos, donde el acento (en sexta sílaba) carga sobre 'hay' y sobre 'va'? No lo cometemos porque esos versos tienen un arranque yámbico: al llegar a la cuarta sílaba (la primera de 'sáuces' y de 'trónco', respectivamente), aún no sabe el verso, quiero decir el lector, igual que ante una encrucijada, por dónde va a decidirse el movimiento rítmico, si por la vía del acento en cuarta y octava sílabas, o si por la del acento en sexta. Más aún: al pasar la rítmica imaginativa por la cuarta, y verla con acento, por un instante cree que la decisión será a favor de la cuarta y octava. Pero el acento en la sexta (y lo que detrás sigue) prueba que todo ha sido engaño. Nadie le podrá quitar, sin embargo, a 'sáuces' y a 'trónco' la ligera intensificación acentual que por este instantáneo y delicioso quid pro quo rítmico han recibido» ${ }^{13}$.

La idea defendida por Navarro Tomás sobre los versos con acento en $4^{\mathrm{a}}$, $6^{\mathrm{a}}$ y $10^{\mathrm{a}}$ sílabas encuentra un apoyo indirecto en la intuitiva lectura de Dámaso Alonso, que diferencia rítmicamente los versos con acento en $4^{\mathrm{a}}$ y $6^{\mathrm{a}}$ sílabas de los endecasílabos comunes con acento en $6^{a}$ sílaba. Pero además su tesis recibe un argumento favorable directo del patrón acentual del endecasílabo sáfico de Horacio, verso que inició la tradición del endecasílabo silabo-tónico, frente al endecasílabo cuantitativo de la tradición griega, como he intentado mostrar en un reciente artículo ${ }^{14}$. Para comprobar los tipos de acentuación que presenta el sáfico horaciano, basta con leer las dos primeras estrofas de Hor. Carm. 4.11:

Est mihi nonum superantis annum plenus Albani cadus, est in horto, Phylli, nectendis apium coronis, est hederae vis multa, qua crinis religata fulges; ridet argento domus, ara castis

13 ALONSO, Dámaso. Poesía española. Madrid: Gredos, 1976, p. 59.

${ }^{14}$ MÁRQUEZ, Miguel Ángel. «El endecasílabo sáfico horaciano, modelo del endecasílabo silabo-acentual». Rhythmica 3-4, 2006, pp. 157-179. 


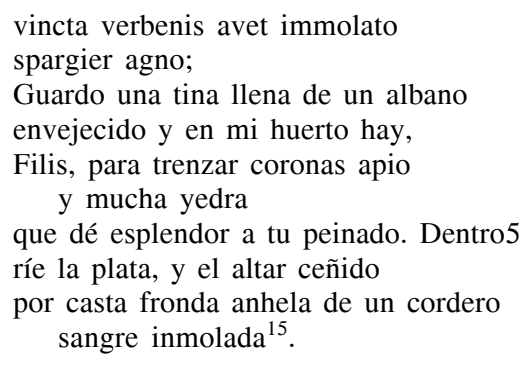

El verso 5, por ejemplo, presenta la acentuación en $1^{\mathrm{a}}, 4^{\mathrm{a}}, 8^{\mathrm{a}}$ y $10^{\mathrm{a}}$ sílabas (múlta, qua crínis religáta fúlges); el verso 3 , en $1^{\mathrm{a}}, 4^{\mathrm{a}}, 6^{\mathrm{a}}$ y $10^{\mathrm{a}}$ sílabas (Phylli, necténdis ápium corónis); y el verso 6 , en $1^{\mathrm{a}}, 4^{\mathrm{a}}, 6^{\mathrm{a}}, 8^{\mathrm{a}}$ y $10^{\mathrm{a}}$ sílabas (rídet argénto dómus, ára cástis). La distribución porcentual de esos tres tipos de acentuación en las Odas de Horacio es también muy relevante:
a) versos con acento en $1^{\mathrm{a}}, 4^{\mathrm{a}}, 8^{\mathrm{a}}$ y $10^{\mathrm{a}}$ :
$29,3 \%$
b) versos con acento en $1^{\mathrm{a}}, 4^{\mathrm{a}}, 6^{\mathrm{a}}$ y $10^{\mathrm{a}}$ :
$53,4 \%$
c) versos con acento en $1^{\mathrm{a}}, 4^{\mathrm{a}}, 6^{\mathrm{a}}, 8^{\mathrm{a}}$ y $10^{\mathrm{a}}$ : $17,3 \%$

Como se ve, el patrón predominante en el sáfico de Horacio hace recaer los acentos en $1^{\mathrm{a}}, 4^{\mathrm{a}}, 6^{\mathrm{a}}$ y $10^{\mathrm{a}}$ sílabas. Los endecasílabos con acentos en $1^{\mathrm{a}}$, $4^{\mathrm{a}}, 8^{\mathrm{a}}$ y $10^{\mathrm{a}}$ sílabas y en $1^{\mathrm{a}}, 4^{\mathrm{a}}, 6^{\mathrm{a}}, 8^{\mathrm{a}}$ y $10^{\mathrm{a}}$ sílabas están bien representados aunque de forma no mayoritaria.

Así pues, la posición de Navarro Tomás al considerar como sáficos los versos con acento en $4^{\mathrm{a}}$ y $6^{\mathrm{a}}$ sílabas no sólo se apoya en la apreciación rítmica subjetiva que distingue esos versos de los endecasílabos comunes, sino también en el origen latino de ese verso silabo-acentual que se inició germinalmente en las Odas de Horacio, y que se generalizó con Séneca, Boecio y otros seguidores medievales, y que pudo servir de modelo para los endecasílabos italianos y, más tarde, para los de Garcilaso de la Vega.

Sin embargo, los versos con acento en $4^{\mathrm{a}}$ y $8^{\mathrm{a}}$ sílabas y en $4^{\mathrm{a}}$ y $6^{\mathrm{a}}$ sílabas no deberían quedar subsumidos bajo el mismo tipo en una clasificación del endecasílabo garcilasiano, porque para el oído español su diferencia rítmica es esencial, como apuntaba Dámaso Alonso y puede comprobarse oyendo los versos 59-60 de la Égloga III:

toda de hiedra revestida y llena, que por el tronco va hasta el altura ${ }^{16}$

${ }^{15}$ La traducción es mía.

${ }^{16}$ El verso con acentos en $4^{\mathrm{a}}$ y $8^{\mathrm{a}}$ presenta un equilibrio y una simetría acentual, de los que carece el verso con acentos en $4^{\mathrm{a}}$ y $6^{\mathrm{a}}$. La tesis de Maury (1846) sobre la simetría de los acentos en el endecasílabo es especialmente aplicable a los versos con acento en $2^{\mathrm{a}}, 6^{\mathrm{a}}$ y $10^{\mathrm{a}}$ (común heroico) y $2^{\mathrm{a}}, 4^{\mathrm{a}}, 8^{\mathrm{a}}$, y $10^{\mathrm{a}}$ (sáfico con acento en $2^{\mathrm{a}}$ ). Esa diferencia perceptible se verá confirmada más adelante mediante el análisis de ritmo interior de ambos versos (§ 2.1). 
Es verdad que los versos con acentos en $4^{\mathrm{a}}$ y $8^{\mathrm{a}}$ y en $4^{\mathrm{a}}$ y $6^{\mathrm{a}}$ remiten a un posible origen común (el sáfico horaciano), pero agruparlos bajo un mismo tipo supone, como coherentemente señalaba Paraíso, considerar el acento alternativo en $6^{\mathrm{a}}$ u $8^{\mathrm{a}}$ como un acento secundario. Esto nos lleva de forma inevitable a tomar la forma con acento en $4^{\mathrm{a}}$ y $10^{\mathrm{a}}$ como patrón acentual mínimo, es decir, como tipo primario ${ }^{17}$, lo que acarrea dos dificultades:

a) considerar como tipo regular el verso con acentos en $4^{\mathrm{a}}$ y $10^{\mathrm{a}}$, que es muy poco frecuente (ningún caso en la Égloga III);

b) aceptar que el endecasílabo admite una secuencia de dos sílabas tónicas separadas por cinco átonas, y esto de forma habitual y no como un excepcional recurso expresivo ${ }^{18}$.

Por eso, preferimos distinguir los versos con acentos en $4^{\mathrm{a}}$ y $8^{\mathrm{a}}$ y en $4^{\mathrm{a}}$ y $6^{\mathrm{a}}$ como dos tipos independientes desde el punto de vista rítmico, de tal modo que en la poesía de Garcilaso se combinarían tres tipos primarios según sus acentos necesario e identificadores: en $6^{\mathrm{a}}$ y $10^{\mathrm{a}}$ sílabas (común); en $4^{\mathrm{a}}, 8^{\mathrm{a}}$ y $10^{\mathrm{a}}$ sílabas (sáfico); y en $4^{\mathrm{a}}, 6^{\mathrm{a}}$ y $10^{\mathrm{a}}$ sílabas. Este tercer tipo, muy frecuente como se verá más adelante ( $\$ 4.2$ ), debería distinguirse nominalmente de los otros dos y, quizá, la denominación de endecasílabo horaciano ${ }^{19}$ no sería inadecuada, puesto que coincide con el patrón acentual predominante en las Odas de Horacio $(53,4 \%)$.

\subsection{El endecasílabo dactílico}

Junto a esos tres tipos primarios, se describe otro endecasílabo, acentuado en $4^{\mathrm{a}}, 7^{\mathrm{a}}$ y $10^{\mathrm{a}}$ sílabas, al que se le denomina dactílico. Domínguez Caparós cita los siguientes versos de Rubén Darío:

Griega es su sangre, su abuelo era ciego; sobre la cumbre del Pindo sonoro ${ }^{20}$

${ }^{17}$ De una manera similar a Henríquez Ureña, quien deriva del $\left(\mathrm{B}^{1}\right)$, acentos en $4^{\mathrm{a}}$ y $10^{\mathrm{a}}$, el $\left(\mathrm{B}^{2}\right)$ y el $\left(\mathrm{B}^{3}\right)$.

${ }^{18}$ Esos versos con acentos en $4^{\mathrm{a}}$ y $10^{\mathrm{a}}$ existen, pero no son frecuentes y su misma rareza permite su gran expresividad; por ejemplo, se cita el verso 9 del Soneto V de Garcilaso de la Vega: «Yo no nací sino para quereros». Por otra parte, el origen de este verso, la original forma del sáfico (B) según Henríquez Ureña, no puede buscarse en el sáfico horaciano, que obligatoriamente acentúa en $6^{\mathrm{a}}$ u $8^{\mathrm{a}}$ sílaba.

${ }^{19}$ Paraíso utiliza ya en su manual el término «horaciano» (PARAÍSO, Isabel, op. cit. p. 128), pero como sinónimo de sáfico y aplicado tanto al verso con acento en $4^{\mathrm{a}}, 8^{\mathrm{a}}$ y $10^{\mathrm{a}}$, como al acentuado en $4^{\mathrm{a}}, 6^{\mathrm{a}}$ y $10^{\mathrm{a}}$. Nuestra propuesta de separación de los dos tipos se acompaña de la distinción terminológica. Sería posible agrupar los versos con acentos en $4^{\mathrm{a}}$ y $8^{\mathrm{a}}$ y en $4^{\mathrm{a}}$ y $6^{\mathrm{a}}$ bajo el tipo sáfico, y distinguirlos como subtipos, por ejemplo, «sáfico propio» frente a «sáfico horaciano», pero esa opción, fiel a su origen común, complicaría la tipología de tipos secundarios y variantes, ya de por sí complicada (cf. § 4.1).

${ }^{20}$ DOMÍNGUEZ CAPARRÓS, José. Métrica española. Madrid: Síntesis, 1993, p. 154. 
Baehr distingue las variantes gallego-portuguesa (acentos en $1^{\mathrm{a}}, 4^{\mathrm{a}}, 7^{\mathrm{a}} \mathrm{y}$ $10^{\mathrm{a}}$ ), y la pura italiana, «que tiene los acentos sólo en la cuarta, séptima y décima sílabas» ${ }^{21}$, y cita como ejemplo un verso de la Égloga I de Garcilaso de la Vega. Se ha señalado también algún otro caso de endecasílabo dactílico; véanse Garcilaso Égloga 1.127 y Soneto 5.5:

Tus claros ojos ¿a quién los volviste?

En esto estoy y estaré siempre puesto ${ }^{22}$

Tanto Henríquez Ureña como Navarro Tomás (1982: 107-108) aceptaron la posibilidad de que en la poesía de Garcilaso de la Vega apareciera el endecasílabo dactílico combinado con los otros tipos ${ }^{23}$. Sin embargo, el propio Navarro Tomás dejó constancia de su ausencia absoluta en la Égloga III (376 versos) y en la Canción IV (169 versos), para la que Garcilaso había utilizado como modelo la Canción I de Petrarca, en la que no faltan ejemplos de ese tipo ${ }^{24}$.

De hecho, en toda la obra de Garcilaso de la Vega, sólo se aducen unos pocos casos que dudosamente pueden ser considerados endecasílabos dactílicos. El propio bosquejo histórico que nos ofrece Navarro Tomás nos hace ver que el endecasílabo dactílico sólo se incorporó como tipo rítmico combinable con el endecasílabo garcilasiano tras el Modernismo. En la poesía contemporánea española, pueden citarse numerosos ejemplos en los que aparece junto a endecasílabos comunes, sáficos y horacianos ${ }^{25}$. En resumen, incluso dejan-

${ }^{21}$ BAEHR, Rudolf. Manual de versificación española. Madrid: Gredos, 1981, p. 141. La variante popular de este tipo de endecasílabos en el verso de gaita gallega: «Tanto bailé con la moza del cura, / tanto bailé que me entró calentura».

${ }^{22}$ E. Torre postula que esos escasos ejemplos de endecasílabos dactílicos en Garcilaso de la Vega podrían resolverse si tenemos en cuenta las diferencias que separan el castellano de Garcilaso de la Vega de nuestro español culto. En el caso de Égloga I, 127, podría considerarse la posibilidad de que el pronombre «los» fuera tónico; así el verso pasaría a portar acentos rítmicos en $2^{\mathrm{a}}, 4^{\mathrm{a}}, 8^{\mathrm{a}}$ y $10^{\mathrm{a}}$, y el acento prosódico en $7^{\mathrm{a}}$ no cumpliría función rítmica. En el caso Soneto V, 5, la solución habría que buscarla en la forma verbal «estaré», cuyo origen perifrástico es «estar he». La acentuación aguda del infinitivo de la perífrasis («estár»), daría como resultado un verso con acentos $2^{\mathrm{a}}, 4^{\mathrm{a}}, 6^{\mathrm{a}}, 8^{\mathrm{a}}$ y $10^{\mathrm{a}}$ sílabas. Del mismo modo, en Égloga III, 7 («Está y estará tanto en mí clavada»), los acentos no recaerían en $2^{\mathrm{a}}, 5^{\mathrm{a}}, 6^{\mathrm{a}}, 8^{\mathrm{a}}$ y $10^{\mathrm{a}}$ sílabas sino que, entendido el verso como «Está y estar ha tanto en mí clavada», obtendríamos un endecasílabo yámbico $\left(2^{\mathrm{a}}, 4^{\mathrm{a}}, 6^{\mathrm{a}}, 8^{\mathrm{a}}\right.$ y $10^{\mathrm{a}}$ sílabas acentuadas). Sin embargo, Antonio Carvajal en comunicación personal me ha apuntado el verso «hinchen el aire de dulce armonía» (Égloga II, 69), cuyo ritmo dactílico es incuestionable.

${ }^{23}$ HENRÍQUEZ UREÑA, Pedro, op. cit. p. 331; NAVARRO TOMÁS, Tomás. «Correspondencia prosódico-rítmica del endecasílabo». Los poetas en sus versos. Barcelona: Ariel, 1982, pp. 107-108.

${ }^{24}$ NAVARRO TOMÁS, Tomás. «El endecasílabo en la tercera Égloga de Garcilaso». Los poetas en sus versos. Barcelona: Ariel, 1982, pp. 121-122. Navarro Tomás dedicó otro trabajo al endecasílabo de Góngora, en el que tampoco aparece anotado ningún endecasílabo dactílico.

${ }^{25}$ Por ejemplo, el endecasílabo «Ayer de cal y de viento sin brida», verso 8 del soneto «Don Quijote trasterrado» (Agenda) de José Hierro, donde aparece junto a endecasílabos comunes, sáficos y horacianos. Sin embargo, entre los 2.652 endecasílabos de Antonio 
do como tema de debate abierto la acentuación dactílica de unos pocos versos, su extrema rareza excluye que el endecasílabo dactílico pueda ser considerado un tipo rítmico más en la poesía de Garcilaso de la Vega ${ }^{26}$.

\section{LA CLÁUSULA CUATERNARIA}

\subsection{Combinación de cláusulas binarias y cuaternarias en los tipos primarios}

En la poesía de Garcilaso de la Vega, los tipos común, sáfico y horaciano presentan entre ellos una compatibilidad rítmica que excluye al dactílico. En este sentido, la pregunta clave sobre la organización rítmica del endecasílabo garcilasiano sería: ¿qué comparten los tres tipos antes dichos que el endecasílabo dactílico no tiene? El elemento que comparten es una secuencia rítmica compuesta por dos sílabas tónicas separadas por tres sílabas átonas: ...ó o o o ó...; veamos los esquemas acentuales de los distintos tipos, marcando en negrita esa secuencia:

$\begin{array}{llllllllllll}\text { común: } & \text { o } & \text { o } & \text { o } & \text { o } & \text { o } & \text { o } & \text { o } & \text { o } & \text { o } & \text { o } & \text { o } \\ \text { sáfico: } & \text { o } & \text { o } & \text { o } & \text { o } & \text { o } & \text { o } & \text { o } & \text { o } & \text { o } & \text { ó } & \text { o } \\ \text { horaciano: } & \text { o } & \text { o } & \text { o } & \text { o } & \text { o } & \text { o } & \text { o } & \text { o } & \text { o } & \text { o } & \text { o } \\ \text { dactílico: } & \text { o } & \text { o } & \text { o } & \text { o } & \text { o } & \text { o } & \text { o } & \text { o } & \text { o } & \text { ó } & \text { o }\end{array}$

El modelo más cómodo para explicar la organización rítmica del endecasílabo es el de cláusula o pies rítmicos. Por ejemplo, en el endecasílabo sáfico (acentos en $4^{\mathrm{a}}, 8^{\mathrm{a}}$ y $10^{\mathrm{a}}$ ) mediante el análisis de cláusulas se obtiene después del primer acento identificador una secuencia de cláusula cuaternaria ${ }^{27}$

Machado, García Abrines sólo ha encontrado un endecasílabo dactílico; y entre los 1.670 de Manuel Machado, aduce 12 casos, de los que 5 no lo son (GARCÍA-ABRINES, Luis. «Los acentos rítmicos endecasílabos en los Machado». Cuadernos Hispanoamericanos. Madrid, pp. 304-307, 1975-1976, p. 1117).

${ }^{26}$ Sobre la exclusión de los endecasílabos dactílicos por los tratadistas del Siglo de Oro, desde Pinciano hasta Caramuel, véase DÍEZ ECHARRI, Emiliano. Teorías métricas del Siglo de Oro. Madrid: CSIC, 1970, pp. 228-229.

${ }^{27}$ De la cláusula cuaternaria se encontraría un vago precedente en el método de análisis del ritmo acentual de Sinibaldo de Mas, cuando habla de «una cuarta sílaba acentuada», es decir, la existencia de tres sílabas no acentuadas que preceden a una acentuada. No compartimos su teoría de las vibraciones y simetrías para explicar la colocación de los acentos, pero en su «cuarta acentuada» vemos un paralelo con nuestra cláusula cuaternaria. Sobre las teorías de Mas, véase DOMínGUEZ CAPARRÓS, José. «Sinibaldo de Mas (1809-1868), tratadista de métrica». Estudios de Métrica. Madrid: UNED, pp. 231-246; y su edicion de la obra de Mas (MAS, Sinibaldo de. Sistema musical de la lengua castellana. DOMÍNGUEZ CAPARRÓS, J. (ed.). Madrid: CSIC, 2001. Por otra parte, en un comentario marginal, Saavedra Molina apunta: «No está de más hacer notar que el endecasílabo (di) puede descomponerse en tres pies xáxx, que es el peónico segundo» (SAAVEDRA MOLINA, Julio. Tres grandes metros: el eneasílabo, el tridecasílabo y el endecasílabo. Santiago de Chile: 
+ cláusula binaria (ó o o o / ó o), empezando a contar a la manera de Navarro Tomás por el tiempo marcado (sílabas $4^{\mathrm{a}}$ y $8^{\mathrm{a}}$ para cada cláusula). Al aceptar este modelo de análisis mediante cláusulas, seguimos la tradición de Bello y Navarro Tomás, que remonta a Nebrija ${ }^{28}$. Sin embargo, al contrario que Navarro Tomás, que sólo utiliza para sus análisis la cláusula binaria y la ternaria, creemos que la cláusula cuaternaria juega un papel rítmico fundamental. La hallamos entre la sílaba $6^{\mathrm{a}}$ y la $10^{\mathrm{a}}$ en los endecasílabos común y horaciano, y entre la $4^{\mathrm{a}}$ y la $8^{\mathrm{a}}$ en el sáfico; y está ausente en el dactílico.

En los sáficos y horacianos que no presentan ningún acento complementario después del primer acento identificador, esa cláusula cuaternaria se combina con una cláusula binaria. Para el sáfico la secuencia es cláusula cuaternaria + cláusula binaria; para el horaciano, cláusula binaria + cláusula cuaternaria ${ }^{29}$. A su vez, el endecasílabo común sin ningún acento complementario después del acento identificador ( $6^{\mathrm{a}}$ sílaba), presenta una cláusula cuaternaria entre ese acento identificador y el acento final. En esa cláusula cuaternaria y en la combinación con la cláusula binaria está la clave del ritmo del endecasílabo de Garcilaso de la Vega.

\subsection{Acentos complementario después del primer acento identificador. Tipos rítmicos secundarios}

Hasta este momento, mediante los acentos necesario e identificadores, hemos establecido los tres tipos rítmicos primarios de endecasílabo. Pero existe también la posibilidad de que, después del primer acento identificador, aparezca un único acento complementario. El lugar de ese acento está fijado tan rigurosamente como el de los acentos identificadores. En el endecasílabo co-

Prensas de la Universidad de Chile, 1946, p. 85), aunque en la página siguiente añade: «Pero, se sabe ya también, que a diferencia de otros metricistas, no concedo gran importancia a estas coincidencias de los números con el ritmo [...]. Porque, lo que la experiencia directa y espontánea me muestra en la dicción de los versos y la percepción de su música, aun después de razonarla, no son números, sino sensación de ritmo, de movimiento, de serpenteo elástico y variado, cuyas curvas se balancean apoyadas en dos vértices de las ondas, con más cuerpo que los otros. Dejemos, pues, los números y volvamos a las siglas» (SAAVEDRA MOLINA, Julio, op. cit. p. 86). Esta es la única ocasión en que se habla de cláusulas acentuales en su obra.

28 «Nebrija designó la cláusula con el nombre clásico de pie, haciendo notar su carácter no cuantitativo sino acentual y anticipando la observación de que los tipos usados en castellano son sólo dos, uno bisílabo a modo de espondeo [...], y otro trisílabo dactílico [...]. Correas usó la misma denominación de pie y distinguió los tipos trocaico, dactílico y anfibráquico [...]. El nombre de cláusula fue introducido por Bello, quien añadió el tipo anapéstico a la serie de Correas» (NAVARRO TOMÁS, Tomás. Métrica española. Barcelona: Labor, 1983 , p. 36 nota 4).

${ }^{29}$ Precisamente esta distinción entre secuencias de ambos versos es otra razón que impulsa a diferenciar dos tipos (sáfico y horaciano), a pesar de que ambos apuntan a un mismo origen, el sáfico de Horacio. 
mún, después del acento en $6^{\mathrm{a}}$ sílaba y antes del acento final $\left(10^{\mathrm{a}}\right.$ sílaba), sólo es posible el acento complementario en $8^{\mathrm{a}}$ sílaba, puesto que los posibles acentos prosódicos en $7^{\mathrm{a}}$ o $9^{\mathrm{a}}$ sílabas serían acentos antirrítmicos. Frente al común, que se organiza con una cláusula cuaternaria, este verso con acentos en $6^{\mathrm{a}}, 8^{\mathrm{a}}$ y $10^{a}$ sílabas presenta dos cláusulas binarias:

y al fondo se dejó calar del río $(84)^{30}$

En el endecasílabo horaciano, después del primer acento identificador ( $4^{\mathrm{a}}$ sílaba) sólo es posible el acento complementario en $8^{\mathrm{a}}$ sílaba, puesto que el acento en $6^{\mathrm{a}}$ sílaba es un acento identificador, y los posibles acentos en $5^{\mathrm{a}}$, $7^{\mathrm{a}}$ o $9^{\mathrm{a}}$ serían antirrítmicos. A su vez, en el sáfico, sólo cabe acentuar complementariamente la sílaba $6^{\mathrm{a}}$. El resultado de la acentuación complementaria tanto para el sáfico como para el horaciano es un verso con acentos en $4^{\mathrm{a}}, 6^{\mathrm{a}}$, $8^{\mathrm{a}}$ y $10^{\mathrm{a}}$ sílabas, es decir, con tres cláusulas binarias consecutivas:

en las templadas ondas ya metidos (281)

De esta manera, junto a los tres tipos primarios (común, sáfico, horaciano), dependientes de los acentos identificadores, los acentos complementarios posteriores al primer acento identificador establecen dos tipos rítmicos secundarios: el verso acentuado en $6^{\mathrm{a}}, 8^{\mathrm{a}}$ y $10^{\mathrm{a}}$, al que podemos denominar común binario o binario-6; y el verso acentuado en $4^{\mathrm{a}}, 6^{\mathrm{a}}, 8^{\mathrm{a}}$ y $10^{\mathrm{a}}$, denominado sáfico binario o binario-4.

\subsection{La cláusula cuaternaria}

La tipología rítmica que proponemos para el endecasílabo de Garcilaso de la Vega, con tres tipos primarios y dos secundarios, se sostiene en un principio que hasta este momento hemos asumido y que ahora debemos verificar: la cláusula cuaternaria no es reducible a la suma de dos binarias.

En general, la tradición crítica que parte de Bello ha postulado que los versos españoles podían analizarse a partir de la alternancia de cláusulas binarias y ternarias. Con frecuencia, ante una cláusula cuaternaria, los especialistas han propuesto su descomposición en dos binarias. Un proceder de este tipo se halla en la Métrica española de Navarro Tomás, quien admite cláusulas de una, dos o tres sílabas ${ }^{31}$. El análisis del endecasílabo heroico que ofrece Navarro Tomás es paradigmático en este sentido:

${ }^{30}$ Este verso, además, presenta un acento en $2^{\mathrm{a}}$ sílaba, que ahora no consideramos porque precede al acento identificador ( $6^{\mathrm{a}}$ sílaba), y que será determinante para establecer las variedades rítmicas $(\$ 3.3)$.

31 Una defensa de las teorías de Navarro Tomás puede verse en CANELLADA, María Josefa. «Sobre ritmo de los versos españoles. (Algunas precisiones a Oldrich Belic)». En Revista de Dialectología y tradiciones populares. Madrid, 1976, n. ${ }^{\circ} 32$, pp. 83-86. 
«Heroico. Empieza con una sílaba en anacrusis. Primer tiempo marcado sobre la segunda; acento intermedio en sexta; las ocho sílabas de que consta el período se reparten en cláusulas bisílabas de ritmo trocaico» ${ }^{32}$.

Los ejemplos de endecasílabo heroico citados por Navarro Tomás (los dos primeros con acento extrarrítmico en $8^{\mathrm{a}}$ sílaba, y el tercero terminado en una palabra tetrasílaba) podrían facilitar esa interpretación ${ }^{33}$. Pero hay otros muchos en los que la partición de la claúsula cuaternaria parece imposible, como en:

ilustre y hermosísima María

El análisis del endecasílabo melódico propuesto por Navarro Tomás resulta aún más improbable ${ }^{34}$. Los intentos de reducir el ritmo del endecasílabo a la alternancia de cláusulas binarias y ternarias se han perpetuado. Así, R. Baehr se remonta a Nebrija en busca de argumentos de autoridad, y concluye de una manera categórica:

«En realidad, de todos los pies de verso mencionados sólo se consideran como existentes de hecho el troqueo y el dáctilo, porque, según los resultados de la foné-

${ }^{32}$ NAVARRO TOMÁS, Tomás. Métrica española. Barcelona: Labor, 1983, p. 198.

${ }^{33}$ Los versos citados por Navarro Tomás son: «La noche se me hizo claro día» (Boscán); «El dulce lamentar de dos pastores» (Garcilaso); y «En sueño y en olvido sepultado (Fray Luis de León). Podría aducirse que «sepultado» tiene un apoyo acentual secundario en la primera sílaba.

34 «Melódico. Dos sílabas en anacrusis. Tiempo marcado en la sílaba tercera; acento intermedio en sexta. La tercera sílaba llena el espacio correspondiente a la parte que representa. El período suma siete sílabas; después de la primera, las siguientes forman tres cláusulas trocaicas» (NAVARRO TOMÁS, Tomás. Métrica española. Barcelona: Labor, 1983, pp. 198-199). Navarro Tomás ofrece un esquema de este tipo de verso: oo ó oo óo oo óo (NAVARRO TOMÁS, Tomás. «Correspondencia prosódico-rítmica del endecasílabo». Los poetas en sus versos. Barcelona: Ariel, 1982, p. 89). Uno de los versos citados es «Alegrando la vista y el oído» (Garcilaso), cuyo ritmo no parece que pueda comprenderse con el esquema propuesto por Navarro Tomás, que requiere: a) que aceptemos la existencia de una cláusula monosilábica ( $3^{\mathrm{a}}$ sílaba); b) que después del acento rítmico en $3^{\mathrm{a}}$ sílaba (-gran-), consideremos que la sílaba $4^{\mathrm{a}}$ (-do) es también marcada rítmicamente; c) y que supongamos un acento secundario en $8^{a}$ sílaba (yel). Una argumentación muy crítica hacia el análisis que practica Navarro Tomás puede verse en MAS, Amédée. «Le mouvement ternaire dans les hendécasyllabes de la troisième Églogue de Garcilaso». Bulletin Hispanique 64, 1962, pp. 539-540. La teoría de Amédée Mas se basa en los grupos fónico-sintácticos, y postula que el $80 \%$ de los versos presentan un movimiento ternario: «Je perçois dans chacun de ces vers, quel que soit le nombre des accents, trois membres, trois mesures séparées par une légère pause ou par une exténuation de la voix» (MAS, Amédée, op. cit. p. 545). Acepta la existencia de endecasílabos bipartitos, pero sólo como contrapunto al movimiento ternario general. En muchos casos su argumentación es en exceso subjetiva; por ejemplo, al dividir así «me darán ocio / y lengua / con que hable». ¿Por qué no podría dividirse «me darán / ocio y lengua / con que hable» o «me darán ocio y lengua / con que hable»? Por no decir, que la sinalefa (o-cioy-) imposibilita su división. En fin, su tesis, al buscar en la curva melódica de las unidades fónico-sintácticas la clave del endecasílabo de Garcilaso, se aleja del ritmo acentual que organiza el endecasílabo español. 
tica experimental, la unidad rítmica debe iniciarse, como en el compás de música, por un acento más o menos fuerte para que el oído español la sienta como tal» ${ }^{35}$.

En un artículo reciente, también Duffell continúa esa tradición que reduce a ritmo yámbico la organización rítmica cuaternaria si se produce en la segunda mitad del endecasílabo:

«Garcilaso converted the Italian endecassillabo into a metre intermediate between syllabic and stress-syllabic by imposing an iambic rhythm on the second half of the line» ${ }^{36}$.

Sin embargo, una parte de la crítica ha aceptado la existencia de las cláusulas mayores de tres sílabas en la versificación española. Por ejemplo, Paraíso anota al respecto:

«Pero las cláusulas de 2 y 3 sílabas, aunque son las más abundantes, no son las únicas. También bastante frecuentes son las de 4 sílabas. Personalmente las denominamos cláusulas peónicas o peones» ${ }^{37}$.

En el endecasílabo garcilasiano, la simple percepción subjetiva del ritmo distingue con facilidad los versos con cláusulas cuaternarias de aquellos otros constituidos sólo a base de cláusulas binarias. La diferencia es patente si comparamos un binario-4 frente a un endecasílabo sáfico, que se distinguen sólo por el acento en $6^{\mathrm{a}}$ sílaba:

pienso mover la voz a ti debida; (12)

libre mi alma de su estrecha roca (13)

Al margen de lo que nuestro oído, más o menos afinado, nos dicte, se encuentran pruebas objetivas en las curvas de tono que proporcionan herramientas como el programa informático Wavesurfer. Como ejemplo se exponen a continuación los análisis de dos endecasílabos de Vicente Aleixandre, recitados por el propio poeta ${ }^{38}$ :

sobre tu dulce hierba acariciada ${ }^{39}$

más allá de la piel se está asomando ${ }^{40}$

\footnotetext{
35 BAEHR, Rudolph, op. cit. pp. 27-28)

${ }^{36}$ DUFFELL, Martin J. «The iambic Pentameter and its Rivals». Rhythmica, 2003, n. ${ }^{\circ}$, p. 61 .

37 PARAÍSO, Isabel, op. cit. p. 91. Paraíso añade en nota a pie de página: «T. Navarro sólo contempla estos dos tipos [de 2 y de 3 sílabas] para su taxonomía. Las cláusulas de 4 sílabas, no especificadas en su teoría, las engloba en la práctica dentro de las trocaicas» (PARAÍSO, Isabel, op. cit. p. 91 nota 16).

${ }^{38}$ Cien años de poesía. Poetas contemporáneos en sus versos. [CD de audio]. Editorial Planeta, 1996.

39 VICENTE ALEIXANDRE. «Canción a una muchacha muerta» v. 6, La destrucción o el amor.

${ }^{40}$ Ibidem. «Rostro final» v. 7, Poemas de la consumación.
} 
El primero de estos versos es un endecasílabo horaciano con una cláusula cuaternaria entre los acentos en $6^{\mathrm{a}}$ y $10^{\mathrm{a}}$ sílabas. El diagrama siguiente muestra el tono de la secuencia «hierba acariciada», que corresponde con la cláusula cuaternaria y el acento final:

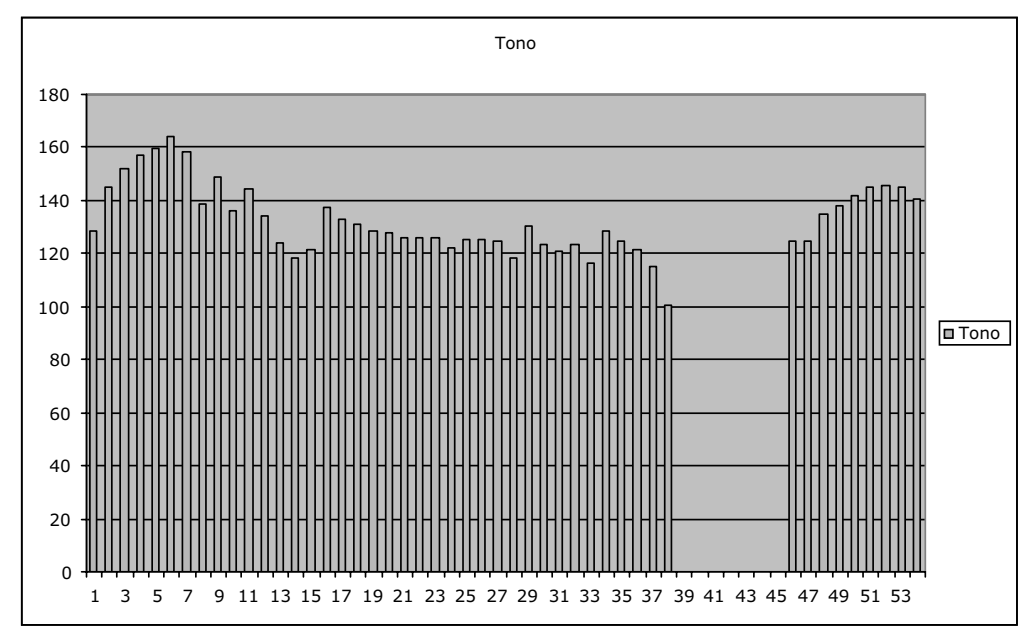

Las dos elevaciones del tono (la primera por encima de los $160 \mathrm{hz}$ y la segunda por encima de los $140 \mathrm{hz}$ ) corrresponden a los dos acentos rítmicos en $6^{\mathrm{a}}$ y $10^{\mathrm{a}}$ sílabas respectivamente (hiér- y -cia-). La depresión entre los dos picos de tono corresponde a las tres sílabas no acentuadas, $7^{\mathrm{a}}, 8^{\mathrm{a}}$ y $9^{\mathrm{a}}$ (-baa-, -ca-, y -ri-).

El segundo verso («más allá de la piel se está asomando») es un endecasílabo binario-6, con dos cláusulas binarias después del primer acento rítmico. El diagrama muestra la secuencia «piel se está asomando»:

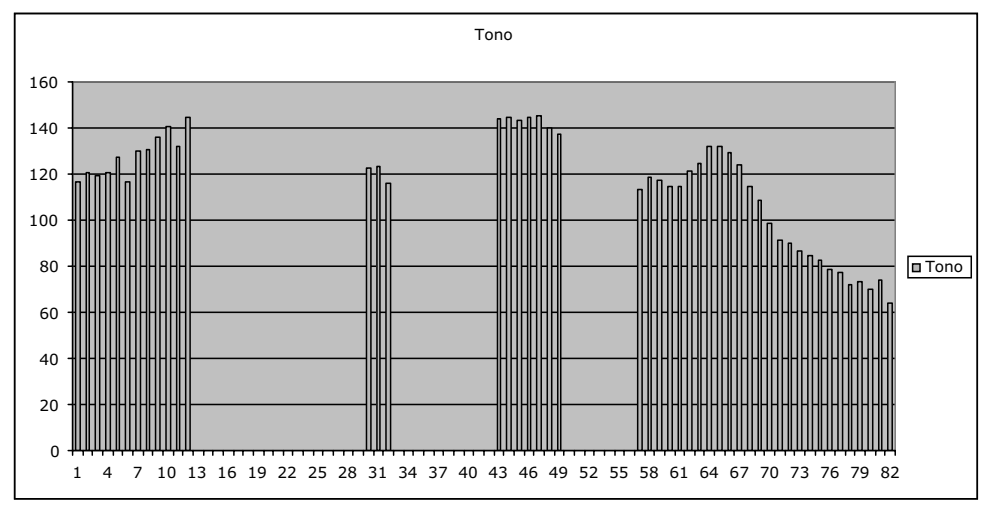


Se observan ahora tres elevaciones de tono: las dos primeras por encima de $\operatorname{los} 140 \mathrm{hz}$ y la tercera por encima de los $130 \mathrm{hz}$, que corresponden a los tres acentos en $6^{\mathrm{a}}$ (piel), en $8^{\mathrm{a}}$ (-tá-a-) y $10^{\mathrm{a}}$ (-man-); entre estas tres elevaciones, dos bajadas en torno a los $120 \mathrm{hz}$, que corresponden a las dos sílabas no acentuadas, en $7^{\mathrm{a}}$ (se-es-) y en $9^{\mathrm{a}}$ (-so-).

En este sentido, todavía es muy útil la información que aportó Gili Gaya en su artículo «La entonación en el ritmo del verso» $(1926)^{41}$. Con los medios técnicos disponibles hace más de ochenta años, Gili Gaya estableció la relación entre ritmo acentual y tono: «Por mi parte no encuentro más que coincidencia frecuente entre el tiempo marcado y la sílaba aguda ${ }^{42}$. Su conclusión más relevante para este trabajo es la siguiente:

«De los comentarios que anteceden puede deducirse que la persona utilizada en mi experiencia ha tenido, en la recitación del soneto que tratamos, una clara tendencia a elevar el tono de las sílabas con acentos fijos» ${ }^{43}$.

En resumen, tanto la impresión subjetiva que nos provoca la lectura de versos con cláusulas cuaternarias y cláusulas binarias, como las curvas de tono que se obtienen a partir de las grabaciones refutan la hipótesis de que una cláusula cuaternaria sea equivalente en el ritmo a dos cláusulas binarias consecutivas. Por el contrario, la cláusula cuaternaria no sólo tiene una existencia independiente y objetiva, sino que además, combinada con la cláusula binaria, constituye el núcleo rítmico del endecasílabo garcilasiano.

\section{ACENTOS COMPLEMENTARIOS ANTES DEL PRIMER ACENTO IDENTIFICADOR. VARIEDADES RÍTMICAS}

\subsection{La exclusión de la cláusula ternaria después del primer acento iden- tificador}

En el interior del verso, después del primer acento identificador, la cláusula cuaternaria combina bien con la binaria, como se ha comprobado en los endecasílabos sáfico y horaciano sin acentos complementarios. Esa misma compatibilidad rítmica permite que se combinen versos puramente cuaterna-

\footnotetext{
${ }^{41}$ GILI GAYA, Samuel. «La entonación en el ritmo del verso». Estudios sobre el ritmo. En PARAÍSO, Isabel (Ed.). Madrid: Istmo, 1993, pp. 43-52.

${ }^{42}$ GILI GAYA, op. cit. p. 51.

${ }^{43}$ GILI GAYA, op. cit. p. 47. En cuanto a los datos que ofrece, obtenidos partir de «trazados quimográficos, aprovechando con frecuencia hojas hechas hace ya tiempo en el laboratorio de fonética del Centro de Estudios Históricos»(Gili Gaya, op. cit. p. 44), merece la pena destacar las medidas a partir del acento en $6^{\mathbf{a}}$ sílaba en los versos que no tienen acento en $8^{\text {a }}$, como el primero («No me mueve, mi Dios, para quererte»): 400-360-380-380-400; frente a los versos en los que el acento en $6^{\mathrm{a}}$ sílaba es seguido por un acento extrarrítmico en $8^{\mathrm{a}}$, como el tercero («ni me mueve el infierno, tan temido»): 480-360-380-320-460, donde se destaca en acento en $8^{\mathrm{a}}$ entre dos bajadas de tono.
} 
rios (común) con otros en los que alternan ambas cláusulas (sáfico y horaciano) o en los que sólo aparece la cláusula binaria (binario-6 y binario-4). Por el contrario, la cláusula ternaria está excluida después del primer acento identificador, y esa exclusión dentro del verso tiene como consecuencia que el endecasílabo llamado dactílico (acentos en $4^{\mathrm{a}}, 7^{\mathrm{a}}$ y $10^{\mathrm{a}}$ sílabas; cláusula ternaria + cláusula ternaria) no aparezca junto a los otros tipos del endecasílabo garcilasiano (cf. 1.4).

\subsection{La cláusula ternaria antes del primer acento identificador}

Esta organización rítmica, en la que se combinan tan armoniosamente las cláusulas binarias y cuaternarias y que excluye a los endecasílabos dactílicos, admite sin ninguna dificultad las cláusulas ternarias siempre que aparezcan antes del primer acento identificador, es decir, antes del acento en $4^{\mathrm{a}}$ sílaba de los tipos sáfico, horaciano y binario-4; y antes del acento en $6^{\mathrm{a}}$ sílaba de los tipos común y el binario-6.

La posición que defendemos es que, en la obra de Garcilaso, los tipos habituales no son compatibles con el dactílico por sus características cláusulas ternarias, al mismo tiempo que comprobamos que los demás tipos admiten la cláusula ternaria cuando se forma antes del primer acento identificador, es decir, entre los acentos en $1^{\mathrm{a}}$ y $4^{\mathrm{a}}$ sílaba en los sáficos y horacianos, cuando se acentúa la primera sílaba, y entre los acentos en $3^{\mathrm{a}}$ y $6^{\mathrm{a}}$ sílaba de los comunes llamados melódicos.

\section{Alegrando la hierba y el oído (64) vido de flores y de sombras lleno (72)}

Esta aparente contradicción se disuelve cuando vemos que la admisión o repulsión de la cláusula ternaria depende de su posición relativa con respecto al primer acento identificador. En el endecasílabo garcilasiano, el primer acento identificador regula la colocación de los siguientes acentos (identificador o complementario), para que sólo se produzcan cláusulas cuaternarias o binarias, excluyendo las ternarias, que, sin embargo, se admiten antes de ese primer acento identificador. En la primera parte del endecasílabo (hasta el primer acento identificador), se admiten unidades binarias y ternarias en el sáfico y el horaciano, y binarias, ternarias y cuaternarias en el común.

Así pues, el primer acento identificador juega un papel esencial en el establecimiento del ritmo del endecasílabo garcilasiano, en cuya segunda parte la alternancia de cláusulas binarias y cuaternarias establece sólidamente su ritmo característico e inconfundible, pero con unas posibilidades de variación muy restringidas. Por el contrario, la secuencia rítmica en la primera parte resulta menos previsible y, por eso mismo, más adecuada a la variación y la expresividad. En este sentido, Navarro Tomás comenta: 
«Las diferencias que determinan el peculiar efecto rítmico de cada tipo resultan de la variable disposición de las cinco primeras sílabas. El resto del verso consta de cláusulas bisílabas uniformemente trocaicas. La sílaba sexta actúa como eje o centro del período. La parte más expresiva del endecasílabo consiste en su primer hemistiquio» ${ }^{44}$.

Tiene razón Navarro Tomás al ligar variabilidad con expresividad, pero no en el primer hemistiquio o antes de la $6^{\mathrm{a}}$ sílaba, sino antes del primer acento identificador (vaya en $4^{\mathrm{a}}$ o $6^{\mathrm{a}}$ sílaba), después del cual no sólo hay esas cláusulas trocaicas que postula Navarro Tomás sino también las cuaternarias, como hemos mostrado en los parágrafos anteriores.

En cualquier caso, la musicalidad del endecasílabo de Garcilaso de la Vega se fundamenta tanto en la armoniosa, estable y previsible combinación de cláusulas binarias y cuaternarias de la segunda parte del verso, como en las expresivas variaciones de su inicio. Sin uno de esos componentes el verso sonaría confuso, sin el otro, tedioso.

\subsection{Variedades rítmicas}

Mientras que los tipos primarios dependen de los acentos identificadores, y los tipos secundarios, de los acentos complementarios posteriores al primer acento identificador, los acentos complementarios anteriores al primer acento identificador generan las variedades rítmicas del endecasílabo.

El común y el binario- 6 presentan su primer acento identificador en $6^{a}$ sílaba. El posible acento prosódico en $5^{\mathrm{a}}$ sílaba no debe ser tenido en cuenta porque se trataría de un acento antirrítmico. El acento en $4^{\mathrm{a}}$ sílaba tampoco es posible en un endecasílabo común, porque cualquier verso con acento en $4^{\mathrm{a}}$ deja de serlo. En estas condiciones, el acento complementario en los tipos común y binario-6 puede recaer en la $1^{\mathrm{a}}, 2^{\mathrm{a}}$ y $3^{\mathrm{a}}$ sílabas, o faltar. Se generan, por tanto, cuatro variedades rítmicas, de las que tres han recibido denominación en la tradición crítica (enfático, heroico y melódico) y la cuarta (sin acento complementario anterior a la $6^{\mathrm{a}}$ sílaba) carece de nombre propio ${ }^{45}$.

${ }^{44}$ NAVARRO TOMÁS, Tomás. «Correspondencia prosódico-rítmica del endecasílabo». Los poetas en sus versos. Barcelona: Ariel, 1982, p. 90.

${ }^{45}$ Véanse los ejemplos citados en $\S 1.2$. La crítica ha señalado la posibilidad de que concurran incluso dos acentos extrarrítmicos, en $1^{\mathrm{a}}$ y $3^{\mathrm{a}}$ sílaba. E. Torre al respecto comenta: «Pueden presentarse muchos otros problemas a la hora de clasificar un verso endecasílabo común. Así, por ejemplo, puede ocurrir que existan o apreciemos acentos secundarios tanto en la sílaba primera como en la tercera: 'hóm-bre-más-a-pe-ná-do-que-nin-gú-no». ¿Clasificaremos este endecasílabo como enfático, por su acento en la primera sílaba, o como melódico, por su acento en la tercera? La respuesta depende del mayor o menor relieve acentual que podamos dar, en la lectura, a una de las dos sílabas, si es que existe esta opción» (TORRE, Esteban. Métrica española comparada. Sevilla: Universidad de Sevilla, 2000, p. 81). 
El sáfico, el horaciano y el binario-4 tienen su primer acento identificador en $4^{\mathrm{a}}$ sílaba. Sin considerar un posible acento prosódico en $3^{\mathrm{a}}$ sílaba, que sería antirrítmico, el acento complmentario podría recaer en $1^{\mathrm{a}}$ o $2^{\mathrm{a}}$ sílaba, y también faltar. Se generan tres variedades rítmicas, que carecen de denominación propia $^{46}$.

\section{TIPOS Y VARIEDADES DEL ENDECASÍLABO GARCILASIANO}

\subsection{Tipología propuesta}

En resumen, la tipología que proponemos incluye cinco tipos rítmicos, de los que tres son primarios y se establecen a partir de los acentos identificadores: común, sáfico y horaciano; y dos son secundarios y se establecen sobre la organización de los acentos identificadores a la que se añade un acento complementario después del primer acento rítmico: binario-6 y binario-4. Véase la siguiente tabla:

\begin{tabular}{|c|c|c|c|}
\hline Clases & denominación & acentuación & cláusulas $^{47}$ \\
\hline \multirow{3}{*}{$\begin{array}{c}\text { Tipos } \\
\text { primarios }\end{array}$} & común & $6^{\mathrm{a}}$ y $10^{\mathrm{a}}$ & cuaternaria \\
\hline & sáfico & $4^{a}, 8^{a}$ y $10^{a}$ & cuaternaria + binaria \\
\hline & horaciano & $4^{\mathrm{a}}, 6^{\mathrm{a}}$ y $10^{\mathrm{a}}$ & binaria + cuaternaria \\
\hline \multirow{2}{*}{$\begin{array}{c}\text { Tipos } \\
\text { secundarios }\end{array}$} & binario-6 & $6^{\mathrm{a}}, 8^{\mathrm{a}}$ y $10^{\mathrm{a}}$ & binaria + binaria \\
\hline & binario-4 & $4^{\mathrm{a}}, 6^{\mathrm{a}}, 8^{\mathrm{a}}$ y $10^{\mathrm{a}}$ & binaria + binaria + binaria \\
\hline
\end{tabular}

Los acentos complmentarios anteriores al primer acento identificador determinan las variedades rítmicas. Los tipos común y binario-6 presentan las mismas cuatro variedades teóricas posibles, con acento complementario en: $1^{\mathrm{a}}$ sílaba (enfático), $2^{\mathrm{a}}$ sílaba (heroico), $3^{\mathrm{a}}$ sílaba (melódico), y sin acento ( $\sin$ nombre propio). Los tipos sáfico, horaciano y binario-4 presentan tres variedades, que carecen de nombre, con acento respectivamente en: $1^{\mathrm{a}}$ sílaba, $2^{\mathrm{a}}$ sílaba y sin acento. En total, suman diecisiete variedades, que ejemplificamos a continuación:

I. Tipo común [acento identificador en $6^{\mathrm{a}}$ ]

1. con acento complementario en $1^{\text {a }}$ (enfático)

Todas, con el cabello desparcido (225) $\left[1^{\mathrm{a}}, 6^{\mathrm{a}}, 10^{\mathrm{a}}\right]$

${ }^{46}$ Véanse los ejemplos citados en $\S 1.2$.

${ }^{47}$ Cláusulas que se generan entre el primer acento identificador y el acento final. No se anotan en esta tabla las cláusulas anteriores al primer acento identificador ni la que tendría como elemento marcado el acento final. 
2. con acento complementario en $2^{\mathrm{a}}$ (heroico) de robles y de peñas varïando; $(172)\left[2^{\mathrm{a}}, 6^{\mathrm{a}}, 10^{\mathrm{a}}\right]$

3. con acento complementario en $3^{\mathrm{a}}$ (melódico) Alegrando la hierba y el oído (64) $\left[3^{\mathrm{a}}, 6^{\mathrm{a}}, 10^{\mathrm{a}}\right]$

4. sin acento antes del primer acento identificador De la esterilidad es oprimido (345) $\left[6^{\mathrm{a}}, 10^{\mathrm{a}}\right]$

II. Tipo binario-6 [acento identificador en $6^{\mathrm{a}}$, complementario en $8^{\mathrm{a}}$ ]

1 . con acento complementario en $1^{\text {a }}$ (enfático) Nise, que en hermosura par no tiene (56) $\left[1^{\mathrm{a}}, 6^{\mathrm{a}}, 8^{\mathrm{a}}, 10^{\mathrm{a}}\right]$

2. con acento complementario en $2^{\mathrm{a}}$ (heroico) Aquella voluntad honesta y pura (1) $\left[2^{\mathrm{a}}, 6^{\mathrm{a}}, 8^{\mathrm{a}}, 10^{\mathrm{a}}\right]$

3. con acento complementario en $3^{\mathrm{a}}$ (melódico) ni desdeñes aquesta inculta parte (35) $\left[3^{\mathrm{a}}, 6^{\mathrm{a}}, 8^{\mathrm{a}}, 10^{\mathrm{a}}\right]$

4. sin acento antes del primer acento identificador de la inmortalidad el alto asiento ${ }^{48}\left[6^{\mathrm{a}}, 8^{\mathrm{a}}, 10^{\mathrm{a}}\right]$

III. Tipo sáfico [acentos identificadores en $4^{\mathrm{a}}, 8^{\mathrm{a}}$ ]

1. con acento complementario en $1^{\mathrm{a}}$ vido de flores y de sombras lleno (72) $\left[1^{\mathrm{a}}, 4^{\mathrm{a}}, 8^{\mathrm{a}}, 10^{\mathrm{a}}\right]$

2. con acento complementario en $2^{\mathrm{a}}$ cestillos blancos de purpúreas rosas $(222)\left[2^{\mathrm{a}}, 4^{\mathrm{a}}, 8^{\mathrm{a}}, 10^{\mathrm{a}}\right]$

3. sin acento antes del primer acento identificador con la fineza de la varia tinta (115) $\left[4^{\mathrm{a}}, 8^{\mathrm{a}}, 10^{\mathrm{a}}\right]$

IV. Tipo horaciano [acentos identificadores en $4^{\mathrm{a}}, 6^{\mathrm{a}}$ ]

1. con acento complementario en $1^{\mathrm{a}}$ nunca dirá jamás que me remueve (27) $\left[1^{\mathrm{a}}, 4^{\mathrm{a}}, 6^{\mathrm{a}}, 10^{\mathrm{a}}\right]$

2. con acento complementario en $2^{\mathrm{a}}$ hará parar las aguas del olvido (16) $\left[2^{\mathrm{a}}, 4^{\mathrm{a}}, 6^{\mathrm{a}}, 10^{\mathrm{a}}\right]$

3. sin acento antes del primer acento identificador por el Estigio lago conducida (14) $\left[4^{\mathrm{a}}, 6^{\mathrm{a}}, 10^{\mathrm{a}}\right]$

V. Tipo binario-4 [acentos en $\left.4^{\mathrm{a}}, 6^{\mathrm{a}}, 8^{\mathrm{a}}\right]^{49}$

1. con acento complementario en $1^{\mathrm{a}}$ pienso mover la voz a ti debida (12) $\left[1^{\mathrm{a}}, 4^{\mathrm{a}}, 6^{\mathrm{a}}, 8^{\mathrm{a}}, 10^{\mathrm{a}}\right]$

2. con acento complementario en $2^{\mathrm{a}}$ (yámbico) el suave olor d'aquel florido suelo (74) $\left[2^{\mathrm{a}}, 4^{\mathrm{a}}, 6^{\mathrm{a}}, 8^{\mathrm{a}}, 10^{\mathrm{a}}\right]^{50}$

3. sin acento antes del primer acento identificador la delicada estambre era distinta (113) $\left[4^{\mathrm{a}}, 6^{\mathrm{a}}, 8^{\mathrm{a}}, 10^{\mathrm{a}}\right]$

Estas diecisiete variedades rítmicas engloban numerosísimas variedades prosódicas $^{51}$, puesto que los acentos antirrítmicos no se han considerado al

${ }^{48}$ De esta variedad no se encuentra ningún caso en la Égloga III. El ejemplo aducido (Garcilaso Elegía I, 203) procede de NAVARRO TOMÁS, Tomás. «Correspondencia prosódico-rítmica del endecasílabo». Los poetas en sus versos. Barcelona: Ariel, 1982, p. 93.

${ }^{49}$ Evidentemente, los acentos en $4^{\mathrm{a}}$ y $10^{\mathrm{a}}$ son rítmicos pero, de los que van en $6^{\mathrm{a}}$ y $8^{\mathrm{a}}$, no puede determinarse cuál es rítmico y cuál complementario.

${ }^{50}$ Se trata de la variedad puramente yámbica, con acento en todas las sílabas pares.

${ }^{51}$ Navarro Tomás apunta 151 variedades constatadas (NAVARRO TOMÁS, Tomás. «Correspondencia prosódico-rítmica del endecasílabo». Los poetas en sus versos. Barcelona: Ariel, 1982, p. 90). 
establecerlas. Por otra parte, esta clasificación no recoge un número muy reducido de casos de versos existentes en los que parece «faltar» algún acento identificador; por ejemplo, los versos con acentos en $4^{\mathrm{a}}$ y $10^{\mathrm{a}}$ sílabas, tan bien comentados por Dámaso Alonso en Poesía española ${ }^{52}$, o los versos acentuados en $2^{\mathrm{a}}, 8^{\mathrm{a}}$ y $10^{\mathrm{a}}$, de los que hay dos casos en la Égloga $\mathrm{III}^{53}$.

\subsection{Análisis cuantitativo: tipos rítmicos}

Un simple listado de los tipos rítmicos, ordenados por frecuencia, con el número de versos y el tanto por ciento sobre el total de versos de la Égloga III, es suficientemente significativo:

$\begin{array}{llr}\text { común: } & 95 & (25,3 \%) \\ \text { horaciano: } & 95 & (25,3 \%) \\ \text { sáfico: } & 77 & (20,5 \%) \\ \text { binario-6: } & 58 & (15,4 \%) \\ \text { binario-4: } & 49 & (13,0 \%) \\ \text { Otros 2: } & & (0,5 \%) \\ \text { Total } & 376 & (100 \%)\end{array}$

No deja de sorprender el que los tipos común y horaciano aparezcan igualados, y que los tres tipos primarios (es decir, sin ningún acento complementario tras el primer acento rítmico) sumen el 71,1\% de los casos. Los tipos secundarios, puramente binarios, están bien representados, pero con una frecuencia menor $(28,4 \%)$. Por último, versos en los que aparentemente «falta» algún acento identificador, por lo que podrían llamarse versos oligotónicos, son rarezas que no superan el $0,5 \%$; encontramos sólo dos versos en toda la Égloga III $^{54}$.

\subsection{Variedades rítmicas}

Ofrecemos tres tablas que resumen los datos obtenidos, en la que además de la denominación que hemos propuesto en este trabajo y el tanto por ciento sobre el total de versos, incluimos dos columnas como recordatorio con los acentos identificadores y complementarios y con las cláusulas que se derivan. Hemos preferido ofrecer los datos en tres tablas, porque las variedades for-

52 ALONSO, Dámaso, op. cit., pp. 90-99.

${ }^{53}$ A veces a los endecasílabos que carecen de algún acento rítmico se les llama endecasílabos «desmayados»; Saavedra Molina llama «indigentes» a los endecasílabos con sólo dos acentos (Saavedra Molina, op. cit. p. 67).

${ }^{54}$ Son los versos 31 («lo menos de lo que'n tu ser cupiere») y 343 («mas todo se convertirá en abrojos»), con acentos en $2^{\mathrm{a}}, 8^{\mathrm{a}}$ y $10^{\mathrm{a}}$ sílabas. 
man tres grupos claramente diferenciados por su frecuencia. En el grupo más frecuente el tanto por ciento varía entre 13,3 y 9,6; en el grupo medianamente representado, entre 5,3 y 4,5; por último, las variedades raras varían entre 2,7 y 0,0 . En la cuarta columna, la doble barra vertical separa las cláusulas anteriores y posteriores con respecto al primer acento identificador.

Variedades frecuentes

\begin{tabular}{|l|c|c|c|}
\hline \multicolumn{1}{|c|}{ Denominación } & $\%$ & Acentos & Cláusulas \\
\hline Común con acento en $2^{\mathrm{a}}$ & 13,3 & {$\left[2^{\mathrm{a}}, 6^{\mathrm{a}}, 10^{\mathrm{a}}\right]$} & cuaternaria $\|$ cuaternaria \\
\hline Horaciano sin acento anterior & 11,4 & {$\left[4^{\mathrm{a}}, 6^{\mathrm{a}}, 10^{\mathrm{a}}\right]$} & $\|$ binaria + cuaternaria \\
\hline Horaciano con acento en $2^{\mathrm{a}}$ & 11,2 & {$\left[2^{\mathrm{a}}, 4^{\mathrm{a}}, 6^{\mathrm{a}}, 10^{\mathrm{a}}\right]$} & binaria $\|$ binaria + cuaternaria \\
\hline Sáfico con acento en $2^{\mathrm{a}}$ & 10,6 & {$\left[2^{\mathrm{a}}, 4^{\mathrm{a}}, 8^{\mathrm{a}}, 10^{\mathrm{a}}\right]$} & binaria $\|$ cuaternaria + binaria \\
\hline Binario-6 con acento en $2^{\mathrm{a}}$ & 9,8 & {$\left[2^{\mathrm{a}}, 6^{\mathrm{a}}, 8^{\mathrm{a}}, 10^{\mathrm{a}}\right]$} & cuaternaria $\|$ binaria + binaria \\
\hline Común con acento en $3^{\mathrm{a}}$ & 9,6 & {$\left[3^{\mathrm{a}}, 6^{\mathrm{a}}, 10^{\mathrm{a}}\right]$} & ternaria $\|$ cuaternaria \\
\hline
\end{tabular}

Variedades frecuentes

\begin{tabular}{|l|c|c|c|}
\hline \multicolumn{1}{|c|}{ Denominación } & $\%$ & Acentos & Cláusulas \\
\hline Sáfico con acento en $1^{\mathrm{a}}$ & 5,3 & {$\left[1^{\mathrm{a}}, 4^{\mathrm{a}}, 8^{\mathrm{a}}, 10^{\mathrm{a}}\right]$} & ternaria $\|$ cuaternaria + binaria \\
\hline Binario-6 con acento en $3^{\mathrm{a}}$ & 4,8 & {$\left[3^{\mathrm{a}}, 6^{\mathrm{a}}, 8^{\mathrm{a}} 10^{\mathrm{a}}\right]$} & ternaria $\|$ binaria + binaria \\
\hline Sáfico sin acento anterior & 4,5 & {$\left[4^{\mathrm{a}}, 8^{\mathrm{a}}, 10^{\mathrm{a}}\right]$} & $\|$ cuaternaria + binaria \\
\hline Binario-4 con acento en $2^{\mathrm{a}}$ & 4,5 & {$\left[2^{\mathrm{a}}, 4^{\mathrm{a}}, 6^{\mathrm{a}}, 8^{\mathrm{a}}, 10^{\mathrm{a}}\right]$} & binaria $\|$ binaria + binaria + binaria \\
\hline Binario-4 sin acento anterior & 4,5 & {$\left[4^{\mathrm{a}}, 6^{\mathrm{a}}, 8^{\mathrm{a}}, 10^{\mathrm{a}}\right]$} & $\|$ binaria + binaria + binaria \\
\hline Binario-4 con acento en $1^{\mathrm{a}}$ & 4,5 & {$\left[1^{\mathrm{a}}, 4^{\mathrm{a}}, 6^{\mathrm{a}}, 8^{\mathrm{a}}, 10^{\mathrm{a}}\right]$} & ternaria $\|$ binaria + binaria + binaria \\
\hline
\end{tabular}

Variedades frecuentes

\begin{tabular}{|l|c|c|c|}
\hline \multicolumn{1}{|c|}{ Denominación } & $\%$ & Acentos & Cláusulas \\
\hline Horaciano con acento en $1^{\mathrm{a}}$ & 2,7 & {$\left[1^{\mathrm{a}}, 4^{\mathrm{a}}, 6^{\mathrm{a}}, 10^{\mathrm{a}}\right]$} & ternaria $\|$ binaria + cuaternaria \\
\hline Común con acento en $1^{\mathrm{a}}$ & 1,6 & {$\left[1^{\mathrm{a}}, 6^{\mathrm{a}}, 10^{\mathrm{a}}\right]$} & cláusula de 5 sílabas? \| cuaternaria \\
\hline Común sin acento anterior & 0,8 & {$\left[6^{\mathrm{a}}, 10^{\mathrm{a}}\right]$} & $\|$ cuaternaria \\
\hline Binario-6 con acento en $1^{\mathrm{a}}$ & 0,8 & {$\left[1^{\mathrm{a}}, 6^{\mathrm{a}}, 8^{\mathrm{a}}, 10^{\mathrm{a}}\right]$} & cláusula de 5 sílabas? $\|$ binaria + binaria \\
\hline Binario-6 sin acento anterior & 0,0 & {$\left[6^{\mathrm{a}}, 8^{\mathrm{a}}, 10^{\mathrm{a}}\right]$} & $\|$ binaria + binaria \\
\hline
\end{tabular}

\subsection{Variedades por tipos}

Variedades del común 55

$\begin{array}{llll}\text { Con acento en } & 2^{\mathrm{a}} & 50 & (52,6 \%) \\ \text { con acento en } & 3^{\mathrm{a}} & 36 & (37,9 \%)\end{array}$

55 En el siguiente listado, el tanto por ciento se refiere al tipo, no al conjunto de toda la Égloga III. 


$\begin{array}{lrrr}\text { con acento en } & 1^{\mathrm{a}} & 6 & (6,3 \%) \\ \text { sin acento } & & 3 & (3,2 \%) \\ \text { total } & & 95 & (100 \%)\end{array}$

Variedades del binario-6

$\begin{array}{llrr}\text { Con acento en } & 2^{\mathrm{a}} & 37 & (63,8 \%) \\ \text { con acento en } & 3^{\mathrm{a}} & 18 & (31,0 \%) \\ \text { con acento en } & 1^{\mathrm{a}} & 3 & (5,2 \%) \\ \text { sin acento } & & 0 & (0,0 \%) \\ \text { total } & & 58 & (100 \%)\end{array}$

Los tipos común y binario-6 presentan distribuciones porcentuales entre las variedades rítmicas muy similares. En los dos tipos, la variedad heroica es mayoritaria $(52,6 \%$ y $63,8 \%)$ y la melódica está bien representada $(37,9 \%$ y $31,0 \%)$; ambas variedades están entre las seis más frecuentes del total. Por el contrario, la variedad enfática y la que no lleva ningún acento antes de la $6^{\mathrm{a}}$ sílaba son muy poco frecuentes; en el tipo binario-6 incluso falta en la Égloga III la variedad sin acento complementario anterior a la $6^{\mathrm{a}}$ sílaba.

Con estos datos relativos, en una clasificación tipológica, no deberían equipararse a las variedades heroica y melódica, muy productivas, la variedad enfática y la que carece de acento anterior a la $6^{\mathrm{a}}$ sílaba, cuya misma rareza les otorga una capacidad expresiva que debería subrayarse en un comentario estilístico, pero que deja a estas variedades en una posición casi tan marginal como la de los endecasílabos en los que parece faltar algún acento identificador («oligotónicos»).

Variedades del horaciano

$\begin{array}{llll}\text { Sin acento } & & 43 & (45,3 \%) \\ \text { con acento en } & 2^{\mathrm{a}} & 42 & (44,2 \%) \\ \text { con acento en } & 1^{\mathrm{a}} & 10 & (10,5 \%) \\ \text { total } & & 95 & (100 \%)\end{array}$

Variedades del sáfico

Con acento en $\quad 2^{\mathrm{a}} \quad 40 \quad(51,9 \%)$

$\begin{array}{llll}\text { con acento en } & 1^{\mathrm{a}} & 20 & (26,0 \%)\end{array}$

sin acento $\quad 17 \quad(22,1 \%)$

total $77 \quad(100 \%)$

Variedades del binario-4

$\begin{array}{llll}\text { Con acento en } & 2^{\mathrm{a}} & 17 & (34,7 \%) \\ \text { sin acento } & & 17 & (37,4 \%) \\ \text { con acento en } & 1^{\mathrm{a}} & 15 & (30,6 \%) \\ \text { total } & & 49 & (100 \%)\end{array}$


En el tipo horaciano, la variedad sin acento complementario anterior a la $4^{\mathrm{a}}$ sílaba y la variedad con acento en $2^{\mathrm{a}}$ son mayoritarias; entre las dos suman casi el $90 \%$ de los casos. A su vez, la variedad con acento en $1^{\mathrm{a}}$ sílaba es minoritaria (10,5\%). En el tipo sáfico, la variedad más frecuente es la que lleva un acento complementario en $2^{\mathrm{a}}$ sílaba $(51,9 \%)$, con una frecuencia el doble que la del sáfico con acento en $1^{\mathrm{a}}$ sílaba, aunque las otras dos variedades estén bien representadas (con acento en $1^{\mathrm{a}}$ sílaba: $26 \%$; y sin acento anterior a la $4^{\mathrm{a}}$ sílaba: $22,1 \%$ ). Por último, en el binario-4, las tres variedades posibles aparecen bastante bien equilibradas.

\section{CONCLUSIONES}

\subsection{Ritmo}

Desde los metricistas del siglo de Oro, nunca se ha dejado de elogiar la musicalidad del endecasílabo de Garcilaso de la Vega, el verso de la poesía culta española desde el siglo XVI. La diferencia con otros metros puramente silábicos reside sin duda en su organización acentual, pero limitarse a marcar los lugares de los acentos imprescindibles es insuficiente para explicar su excelencia rítmica y estética. La clave se encierra en la secuencia de sílabas tónicas y átonas, en el patrón acentual escondido entre tantas posibilidades de acentuación prosódica.

Más allá de los prejuicios clasicistas sobre la exclusividad de cláusulas bisílabas y trisílabas, el endecasílabo garcilasiano presenta, en la mayoría de sus variedades, una secuencia de dos sílabas tónicas separadas por tres átonas. Aceptando el modelo clausular de análisis, esa secuencia se define como cláusula cuaternaria. Esta cláusula no es reducible a dos cláusulas binarias consecutivas: tanto la impresión subjetiva del ritmo como las curvas de tono refutan esa operación habitual en los estudios de métrica. Por el contrario, la cláusula cuaternaria existe objetiva e independientemente y además, combinada con la cláusula binaria, constituye el núcleo rítmico del endecasílabo garcilasiano.

El primer acento identificador (ya sea en $4^{\mathrm{a}}$ sílaba, ya sea $6^{\mathrm{a}}$ ) divide el verso en dos partes diferenciadas con respecto al ritmo. En la primera parte, la mayor libertad acentual aporta variedad y expresividad al endecasílabo. En la segunda, la estricta alternancia de cláusulas binarias y cuaternarias asegura un ritmo constante y reconocible. Así, la musicalidad del endecasílabo de Garcilaso de la Vega se fundamenta tanto en la armoniosa, estable y previsible combinación de cláusulas binarias y cuaternarias de la segunda parte del verso, como en las expresivas variaciones de su inicio. Como se dijo en $\S 3.2$, sin uno de esos componentes el verso sonaría confuso, sin el otro, tedioso. 


\subsection{Tipos rítmicos}

La tipología que se ha propuesto se basa en unos criterios coherentes. Partiendo de los acentos identificadores y el acento necesario en $10^{\mathrm{a}}$ sílaba, se clasifican los endecasílabos en tres tipos primarios: común (acentos en $6^{\mathrm{a}}$ y $10^{\mathrm{a}}$ ), sáfico $\left(\right.$ acentos en $4^{\mathrm{a}}, 8^{\mathrm{a}}$ y $\left.10^{\mathrm{a}}\right)$ y horaciano $\left(4^{\mathrm{a}}, 6^{\mathrm{a}}\right.$ y $\left.10^{\mathrm{a}}\right)$. A ellos se unen dos tipos secundarios que se generan por el único acento complementario admisible después del primer acento identificador: el binario- 6 o común binario (acentos en $6^{\mathrm{a}}, 8^{\mathrm{a}}$ y $10^{\mathrm{a}}$ ) y el binario-4 o sáfico binario (acentos en $4^{\mathrm{a}}, 6^{\mathrm{a}}, 8^{\mathrm{o}}$ y $\left.10^{\mathrm{a}}\right)$.

La pertinencia de esta tipología se ve confirmada por los datos porcentuales en la Égloga III de Garcilaso de la Vega (\$ 4.2). Los tipos primarios (común, horaciano y sáfico) representan el $71,1 \%$ del total, mientras que los secundarios (binario-6 y binario-4) sólo el $28,4 \%$. Los versos que no se adaptan a este tipología son rarezas rítmicas muy singulares. De esos datos, podemos extraer la distribución porcentual de los versos según las cláusulas que se combinan después del primer acento identificador:

con cláusula cuaternaria (común): $25,3 \%$

con cláusulas binarias (binario-6 y binario-4): $28,4 \%$

con los dos tipos de cláusula (horaciano y sáfico): 45,8\%

A partir de estos datos, la conclusión es que el ritmo del endecasílabo no se organiza exclusivamente sobre una serie de yambos, puesto que sólo el $28,4 \%$ responde a ese ritmo. Por el contrario, queda patente un equilibrio muy armonioso entre la cláusula cuaternaria y la binaria: casi la mitad de los versos combinan en su interior las dos cláusulas; un cuarto de los versos se constituye con una sola cláusula cuaternaria; y un poco más de un cuarto de los versos se basa sólo en la binaria.

\subsection{Variedades rítmicas}

Mediante los acentos complementarios anteriores al primer acento rítmico se distinguen hasta diecisiete variedades rítmicas, algunas con nombres tradicionales (enfático, heroico, melódico) pero la mayoría sin denominación propia, que engloban numerosas posibilidades de acentuación prosódica, puesto que los acentos antirrítmicos no deben ser considerados como criterios de clasificación.

Estas diecisiete variedades teóricas pueden dividirse en grupos de frecuencia. Las seis más abundantes (cf. Tablas en $§ 4.3$ ) representan el 66\% del total; como cabía esperar por la tradición crítica, la variedad más frecuente es la del común heroico (acentos en $2^{\mathrm{a}}, 6^{\mathrm{a}}$ y $10^{\mathrm{a}}$ ), pero debe dejarse constancia de que las dos variedades que le siguen son la del horaciano sin acento anterior (acen- 
tos en $4^{\mathrm{a}}, 6^{\mathrm{a}}$ y $10^{\mathrm{a}}$ ) y la del horaciano con acento en $2^{\mathrm{a}}$ (acentos en $2^{\mathrm{a}}, 4^{\mathrm{a}}, 6^{\mathrm{a}}$ y $\left.10^{\mathrm{a}}\right)$. Entre las variedades menos frecuentes se encuentran las del común enfático (acentos en $1^{\mathrm{a}}, 6^{\mathrm{a}}, 10^{\mathrm{a}}$ ) y la del binario- 6 enfático (acentos en $1^{\mathrm{a}}, 6^{\mathrm{a}}$, $8^{\mathrm{a}}$ y $\left.10^{\mathrm{a}}\right)$.

En resumen, creemos que la clasificación del endecasílabo que se ha ofrecido es coherente porque evita la mezcla de tipos y variedades: así, no ocupan el mismo nivel clasificatorio el endecasílabo enfático y el endecasílabo sáfico, porque el enfático es una mera variedad de las cuatro que presenta el endecasílabo común (y muy rara), y el sáfico es un verdadero típico rítmico con tres variedades diferenciables. En segundo lugar, esta tipología no equipara sin más las diferentes posibilidades teóricas, sino que pretende distinguirlas según la importancia cuantitativa que cada una tiene en la versificación de Garcilaso de la Vega; por ejemplo, las dos variedades del heroico (acentos en $2^{\mathrm{a}} 6^{\mathrm{a}}$ y $10^{\mathrm{a}}$, o en $2^{\mathrm{a}}, 6^{\mathrm{a}} 8^{\mathrm{a}}$ y $10^{\mathrm{a}}$ ) suman más del $23 \%$ de los versos de la Égloga III; las dos variedades del enfático (acentos $1^{\mathrm{a}}, 6^{\mathrm{a}}$ y $10^{\mathrm{a}}$ o en $1^{\mathrm{a}}, 6^{\mathrm{a}}, 8^{\mathrm{a}}$ y $10^{\mathrm{a}}$ ) apenas llegan al $2,4 \%$. Por último, esta tipología otorga un papel decisivo al primer acento identificador, que divide el endecasílabo en dos partes rítmicamente diferenciables: en la primera parte, los acentos complementarios aportan variedad y expresividad; en la segunda parte, la rigurosa regulación de los acentos identificadores y complementario fundamenta el ritmo del endecasílabo garcialasiano en la alternancia de cláusulas binarias y cuaternarias.

Fecha de recepción: 5 de mayo de 2008

Fecha de aceptación: 25 de noviembre de 2008 